\title{
COLLAGEN DRESSING: A PROSPECTIVE RANDOMIZED TRIAL OF COLLAGEN SHEET AS A BIOLOGICAL DRESSING AND ITS ROLE IN THE CHRONIC NON-HEALING WOUNDS
}

\author{
M. Ramula1 , J. Joyce Prabhakar², N. Lakshmipathy33, Vaithiswaran Arikrishnan ${ }^{4}$ \\ ${ }^{1}$ Associate Professor, Department of Surgery, Chengalpattu Medical College, Chengalpattu. \\ ${ }^{2}$ Assistant Professor, Department of Surgery, Chengalpattu Medical College, Chengalpattu. \\ ${ }^{3}$ Assistant Professor, Department of Surgery, Chengalpattu Medical College, Chengalpattu. \\ 4Junior Resident, Department of Surgery, Chengalpattu Medical College, Chengalpattu.
}

\section{ABSTRACT}

\section{BACKGROUND}

Collagen is the most abundantly present connective tissue. In higher animals, primarily as extracellular insoluble fibres and the fibres account for large part of organic mass of skin, tendon, blood vessel, bone teeth, cornea and vitreous humour. Collagen also provides the framework of parenchymal organs and basement membrane. The collagens constitute a family of proteins selected during evolution for the execution of several (mainly structural) functions. During the process of evolution of multicellular organisms, a family of structural proteins was selected by both environmental influences and the functional requirements of the animal organism and developed to acquire varying degrees of rigidity, elasticity and strength. These proteins are known collectively as collagen and the chief examples among its various types are present in the skin, bone, cartilage, smooth muscle and basal lamina. Collagen is the most abundant protein in the human body representing $30 \%$ of its dry weight. The collagens are produced by several cell types and are distinguishable by their molecular compositions, morphologic characteristics, distribution, functions and pathologies. More than 20 types of collagen have been identified and designated with Roman numerals; the most important of these are listed in Table 5-3. They are classified into the following four categories according to their structure and general functions.

\section{METHODS}

Collagen dressing with facilities available in government setup.

\section{RESULTS}

The overall healing rate with collagen sheet is $70.14 \%$ within a relatively short period.

\section{CONCLUSION}

Collagen dressing is superior to conventional dressing.

\section{KEYWORDS}

Biological Dressing, Collagen Sheet, Wound Healing.

HOW TO CITE THIS ARTICLE: Ramula M, Prabhakar JJ, Lakshmipathy N, et al. Collagen dressing: a prospective randomized trial of collagen sheet as a biological dressing and its role in the chronic non-healing wounds. J. Evolution Med. Dent. Sci. 2016;5(55):37183721, DOI: $10.14260 /$ jemds/2016/853

\section{INTRODUCTION}

Collagen is a large, rod-shaped protein composed of three polypeptide chains arranged in a triple-helix configuration. It is the most common protein in the body and is a widely used biologic implant material. AlloDerm (LifeCell Corp., Branchburg, NJ) is an acellular, structurally and biochemically intact human dermal graft that is used for cosmetic and reconstructive soft-tissue augmentation. Donated human skin is denuded of epithelium, freeze-dried and decellularised through a special process that preserves the bioactive components without damaging the extracellular dermal matrix and basement membrane architecture. The resulting graft serves as a framework to support cellular repopulation, revascularization at the surgical site and soft tissue regeneration by the recipient's own cells.

Financial or Other, Competing Interest: None.

Submission 04-06-2016, Peer Review 29-06-2016,

Acceptance 04-07-2016, Published 08-07-2016.

Corresponding Author:

Dr. M. Ramula,

\#A-14, Old G. S. T. Road,

Alagesan Nagar,

Chengalpattu-603001.

E-mail: ramuladurai@gmail.com

DOI: $10.14260 /$ jemds $/ 2016 / 853$

Animal studies demonstrate that AlloDerm is nontoxic with no elicitation of an inflammatory response. It has a shelflife of up to 2 years under standard refrigeration and is rehydrated immediately before use with normal saline or lactated Ringer solution. The most common uses for AlloDerm include fascial defect repair, wound coverage, lip enhancement, dorsal nasal augmentation, correction of depressed scars and liposuction defects and nipple augmentation. Depending on the degree of soft tissue replacement needed, AlloDerm can be used as a single layer or stacked in multiple layers. The graft can be pulled through subdermal tunnels created through small incisions. Cymetra is a particulate form of AlloDerm delivered by injection and is most commonly used (as is collagen and hyaluronic acid) for lip augmentation and the filling of prominent nasolabial folds some as sheets for ulcers.[1]

Collagen synthesis depends on the expression of several genes and several post-translational events. It should not be surprising, therefore that a large number of pathological conditions are directly attributable to insufficient or abnormal collagen synthesis.

Certain mutations in the 1 (I) or 2 (I) genes lead to osteogenesis imperfecta. Many cases of osteogenesis imperfecta are due to deletions of all or part of the 1 (I) gene. 
However, a single amino acid change is sufficient to cause certain forms of this disease, particularly mutations involving glycine. Glycine must be at every third position for the collagen triple helix to form.

In addition to these disorders, several diseases result from an over-accumulation of collagen. In progressive systemic sclerosis, almost all organs may present an excessive accumulation of collagen (Fibrosis). This occurs mainly in the skin, digestive tract, muscles and kidneys causing hardening and functional impairment of the implicated organs. ${ }^{[2]}$

Keloid is a local swelling caused by abnormal amounts of collagen that form in scars of the skin. Keloids, which occur most often in individuals of black African descent, can be a troublesome clinical problem to manage; not only can they be disfiguring, but excision is almost always followed by recurrence.

Vitamin C (Ascorbic acid) deficiency leads to scurvy, a disease characterized by the degeneration of connective tissue. Without this vitamin, fibroblasts synthesize defective collagen and the defective fibers are not replaced. This process leads to a general degeneration of connective tissue that becomes more pronounced in areas, in which collagen renewal takes place at a faster rate. The periodontal ligament that holds teeth in their sockets has a relatively high collagen turnover; consequently, this ligament is markedly affected by scurvy, which leads to a loss of teeth. Ascorbic acid is a cofactor for proline hydroxylase, which is essential for the normal synthesis of collagen. Table 5-4 lists a few examples of the many disorders caused by failure of collagen biosynthesis.

Because collagen type I is so abundant, its synthesis has been studied most thoroughly. Synthesis of this important protein involves several steps, which are summarized in Figure 5-11:

1. Polypeptides called procollagen chains are produced on polyribosomes bound to membranes of RER and translocated into the cisternae and the signal peptide is clipped off.

2. Hydroxylation of proline and lysine begins after the peptide chain has reached a certain minimum length and is still bound to the ribosomes. The enzymes involved are prolyl hydroxylases and lysyl hydroxylase and the reactions require $\mathrm{O}_{2}, \mathrm{Fe}^{2+}$ and ascorbic acid (vitamin $\mathrm{C}$ ) as co-factors. ${ }^{[3]}$

3. Glycosylation of some hydroxylysine residues occurs with the various collagen types having different amounts of galactose linked to hydroxylysines.

4. Both the amino- and carboxyl-terminal ends of each chain make up non-helical portions of the polypeptides, sometimes called the extension propeptides, which may help ensure that the appropriate chains.1,2 assemble in the correct position as a triple helix. In addition, the nonhelical propeptides make the resulting procollagen molecule soluble and prevent its premature intracellular assembly and precipitation as collagen fibrils. Procollagen is transported through the Golgi network and undergoes exocytosis to the extracellular environment.

5. Outside the cell, specific proteases called procollagen peptidases remove the extending propeptides, converting the procollagen molecules to collagen molecules. These are now capable of self-assembly into polymeric collagen fibrils, usually in specialized niches near the cell surface.
6. In some collagen types, fibrils aggregate to form fibers. Certain proteoglycans and types of collagen (types $\mathrm{V}$ and $\mathrm{XI}$ ) participate in the aggregation of collagen molecules to form fibrils and in the formation of fibers from fibrils. FACIT collagens help stabilize the molecules in collagen fibrils and fibers and bind these structures to other components of the ECM.

7. Fibrillar structure is reinforced further by the formation of covalent cross-links between assembled collagen molecules, a process catalysed by the extracellular enzyme lysyl oxidase.

\section{AIM OF THE STUDY}

To study the role of collagen in wound healing, especially with chronic ulcers and to assess the advantage of collagen sheet dressing over conventional dressings. ${ }^{4}$, to evaluate the patient compliance and to prevent the patient from chronic nonhealing ulcers.

\section{MATERIALS AND METHODS}

All cases of chronic ulcer with varying aetiology were admitted with varying duration in the study. The average age of the patient was 35 yrs. and the youngest being 16 and the oldest was 75 yrs.

From all cases consent was got with duration of 3 months. All types of ulcer were admitted without complication like bony, joint, deeper structure involvement.

Ulcer of varying size with total number of 30 cases were admitted under collagen sheet study and for observation equal no. of cases were admitted for conservative dressing.

\section{Distribution of Cases}

\begin{tabular}{|c|c|c|c|c|}
\hline $\begin{array}{c}\text { Sl. } \\
\text { No. }\end{array}$ & $\begin{array}{c}\text { Types of } \\
\text { Ulcer }\end{array}$ & $\begin{array}{c}\text { No. of } \\
\text { Cases }\end{array}$ & Duration & $\begin{array}{c}\text { Percentage } \\
\text { of Cases }\end{array}$ \\
\hline 1 & Traumatic Ulcer & 8 & $3-6$ Months & $26.66 \%$ \\
\hline 2 & Diabetic Ulcer & 6 & $\begin{array}{c}6 \text { Months } \\
-1 \text { Years }\end{array}$ & $20 \%$ \\
\hline 3 & Trophic Ulcer & 6 & $3-5$ yrs. & $20 \%$ \\
\hline 4 & Venous Ulcer & 4 & $1-2$ yrs. & $13.33 \%$ \\
\hline 5 & Pressure Ulcer & 3 & $4-6$ Months & $10 \%$ \\
\hline 6 & $\begin{array}{c}\text { Post-operative } \\
\text { Wound }\end{array}$ & 2 & $3-5$ Months & $6.66 \%$ \\
\hline 7 & Nonspecific & 1 & $>1$ yrs. & $3.33 \%$ \\
\hline \multicolumn{5}{|c|}{ Distribution of Cases } \\
\hline
\end{tabular}

On Admission all Patients were made to undergo following Investigations

1. Urine sugar and albumin.

2. Blood: Hb, TC, DC, ESR.

3. Blood urea, sugar, creatinine.

4. X-Ray chest.

5. X-Ray local part.

6. Wound swab.

7. Nutritional status and other systemic comorbidities.

\section{How to Apply it to the Wound}

Note: Collagen sheet comes in a sterile double packing as a transparent, pliable sheet with a back and a top protection cover sheet of medical grade synthetic polymer.

- Upon opening the sterile package, the top sheet of polymer can be removed carefully and soaked in sterile water/normal saline solution for 2 to 3 minutes to easily remove the backing sheet. 
- $\quad$ Prepare wound area using standard methods to ensure wound is free of debris and necrotic tissue. An initial surgical debridement of the wound may be necessary to ensure the wound edges contain viable tissue.

- Do not apply ointment or any greasy cream on the site prior to collagen application.

- Do not try to over stretch the membrane.

- Collagen sheet can be applied on either of its surface and it adheres to the wound instantly. ${ }^{5}$ In case of dry wounds, sprinkle sterile saline solution on the surface and apply.

- If there is a need to retain the dressing in place, the perimetry can be taped or sutured if preferred by the doctor. If a secondary dressing is required, the backing sheet of polymer can be placed first prior to making a bandage around to prevent any unwanted adherence of the bandage to our collagen sheet.

- Repeated dressing is not required, unless the wound is infected or found to accumulate excessive exudate underneath that cannot be drained by making slit openings in the dressing.

- Collagen sheet peels off as the wound heals. ${ }^{6}$ However, in some circumstances it may need to be moistened with saline before removal.

- For donor site application after surgical removal of donor tissue, arrest bleeding by conventional methods, clean the site and apply collagen dressing.

- Concurrent systemic therapy may be given as prescribed in infected cases and non-infected cases for better and faster results.

\section{Precaution for its Usage}

Always handle collagen sheet using aseptic techniques. Collagen sheet should not be applied until excessive exudates.[7] bleeding, acute swelling and infection is controlled. If air pockets appear beneath the applied collagen sheet, it can be gently pressed and removed using a sterile methods. In case of localized bulging due to fluid accumulation beneath collagen sheet, a small incision can be made to exude fluid. This incision can be patched with a small piece of collagen sheet adhering to the original applied collagen sheet. After application use an appropriate, non-adherent, secondary dressing to maintain a moist wound environment. Frequency of secondary dressing change will depend on the volume of exudate produced and type of dressing used. ${ }^{8}$ Do not forcibly remove sections of collagen sheet that may adhere to the wound. Alternatively, collagen sheet may form a caramel coloured gel, which can be rinsed away with gentle irrigation.

\section{Study Group Data Analysis}

- Age, sex, place, comorbidities, peripheral vascular disease.

- Mode of injury or onset of wound.

- Disease associated.

- Anatomical site.

- Vascularity of affected anatomical part (Doppler Study).

\section{RESULTS FROM STUDY}

The overall healing rate with collagen sheet is $70.14 \%$ within a relatively short period and the individual case results were given below in tab.

\begin{tabular}{|c|c|c|c|c|}
\hline $\begin{array}{c}\text { Sl. } \\
\text { No. }\end{array}$ & $\begin{array}{c}\text { Types of } \\
\text { Ulcer }\end{array}$ & $\begin{array}{c}\text { No. } \\
\text { of } \\
\text { Cases }\end{array}$ & $\begin{array}{c}\text { No. of Cases } \\
\text { with } \\
\text { Excellent } \\
\text { Healing } \\
\text { Results }\end{array}$ & $\begin{array}{c}\text { Percentage } \\
\text { of } \\
\text { Cases }\end{array}$ \\
\hline 1 & $\begin{array}{c}\text { Traumatic } \\
\text { ulcer }\end{array}$ & 8 & 7 & $87.5 \%$ \\
\hline 2 & $\begin{array}{c}\text { Diabetic } \\
\text { Ulcer }\end{array}$ & 6 & 4 & $66.6 \%$ \\
\hline 3 & $\begin{array}{c}\text { Trophic } \\
\text { Ulcer }\end{array}$ & 6 & 3 & $50.0 \%$ \\
\hline 4 & $\begin{array}{c}\text { Venous } \\
\text { Ulcer }\end{array}$ & 4 & 3 & $75.0 \%$ \\
\hline 5 & $\begin{array}{c}\text { Pressure } \\
\text { Ulcer }\end{array}$ & 3 & 2 & $66.6 \%$ \\
\hline 6 & $\begin{array}{c}\text { Post- } \\
\text { Operative } \\
\text { Wound }\end{array}$ & 2 & 1 & $50.0 \%$ \\
\hline 7 & Nonspecific & 1 & 0 & $00.0 \%$ \\
\hline
\end{tabular}

\section{DISCUSSION}

Bovine collagen is very similar to human collagen prepared from bovine collagenous tissues with a series of chemical and enzymatic procedures followed by chemical cross-linking and sterilization. The collagen sheet is retained in the tissue and gradually absorbed by inflammatory cellular activity. The fibrous tissue is then replaced by fibroblasts. Granulation tissue developed at a normal rate and the cellular events are similar to the events occurring in normal wounds. Deamidation of collagen makes it a useful and important biopolymer in the field of bio-material engineering. Deamidation results in a collagen with improved solubility as well as swelling properties, which are the prerequisites for a bio-material.[9] Deamidation collagen has high viscosity and very high hydroxyproline content like native collagen. ${ }^{[10]}$ Collagen sheets are very useful in first- and second degree burns.[11]

\section{Advantages}

- Cost of treatment comes down.

- Pain associated with dressing can be avoided.

- Especially in children, the trauma of dressing is avoided.

- Protects against infection.

- Avoids evaporative water loss.

- No threat of HIV or Hepatitis infection as bovine material is obtained from countries free of Bovine Spongiform Encephalopathy (BSE).

- Long shelf-life (5 years) under normal storage conditions.

- Low antigenicity.

- Ensures non-toxicity to the biological environment where it is applied.

\section{CONCLUSION OF STUDY}

In our country as the population explosion poses a threat to health, we have to meet the demands of increased no. of patients with the presently available infrastructure. In this way in the treatment of chronic ulcer, collagen sheet as biological dressing is advantageous in all the aspects compared to conventional method in vogue. Collagen sheets can be recommended and can be used effectively in all the chronic ulcer as a routine. 
In conclusion, the collagen sheets used in chronic nonhealing has several advantages over the conventional dressing method. This method is easy to perform, no need for frequent dressing changes, prevents evaporative skin loss of water and electrolytes and free from pain of frequent dressing change especially in children. The chances of infection is also minimal since the collagen forms a protective cover. The wound healing process is quick and the scar formed is cosmetically acceptable.

\section{REFERENCES}

1. Sclafani AP, Romo T, Jacono AA, et al. Evaluation of acellular dermal graft (alloderm) sheet for soft tissue augmentation. JAMA Facial Plastic Surgery 2001;3(2):101-3.

2. Rodnan GP, Lipinski E, Luksick J. Skin thickness and collagen content in progressive systemic sclerosis and localized scleroderma. Arthritis Rheum 1979;22(2): 130-40.

3. Diegelmann RF, Bernstein L, Peterkofsky B. Cell-free collagen synthesis on membrane-bound polysomes of chick embryo connective tissue and the localization of prolyl hydroxylase on the polysome-membrane complex. Journal of Biological Chemistry 1973;248(18);6514-21.
4. Onkarsingh S, Guptha SS, Mohan S, et al. Collagen dressing vs conventional dressing in chronic wound: a retrospective study. Journal of Cutaneous and Aesthetic Surgery 2011;4(1);12-16. doi 10.4103/0974-2077.79180

5. Brett D. A review of collagen and collagen based dressings. Wounds 2008;20(12):347-56.

6. Ramakrishna MK, Babu M, Jayaramamn V, et al. Untold story of collagen dressing. Indian Journal of Burns 2014;22(1):33-36.

7. Quinn KJ, Courtney JM, Gaylor JD, et al. Principle of burn dressing. Biomaterials 1985;6(6):369-77.

8. Brett D. A review of collagen and collagen based dressing. Medscape General Surgery Wounds 2008;20(12).

9. Ramakrishnan KM, Babu M, Mathivanan, et al. Advantages of collagen based dressings in the management of superficial and partial thickness burns in children. Ann Burns and Fire Disasters 2013;26(2):98-104.

10. Mariappan N. Collagen dressing for thermal burns. SJAMS 2015;3(1A):58-61.

11. Purana T, Babu M. Collagen based dressing-a review. Burns 2000;26(1):54-62. 